\section{Absolute Threshold}

Mark Mennemeier

Neurobiology and Developmental Sciences,

University of Arkansas for Medical Sciences,

Little Rock, AR, USA

\section{Synonyms}

Stimulus threshold

\section{Definition}

The absolute threshold is the smallest amount of stimulus energy necessary to produce a sensation of the stimulus. The idea that a mental event has to exceed some critical amount is central to the concept of a sensory threshold. The absolute threshold refers to the measurement of that critical amount.

\section{See Also}

- Just Noticeable Differences

\section{References and Readings}

Gescheider, G. A. (1997). Psychophysics: The fundamentals (3rd ed.). London: Erlbaum, Chapter 1. 